\title{
The N-Terminal Region of Soybean PM1 Protein Protects Liposomes during Freeze-Thaw
}

\author{
Liyi Chen ${ }^{1,+}$, Yajun Sun ${ }^{1,+}$, Yun Liu ${ }^{1}$, Yongdong Zou ${ }^{2}$, Jianzi Huang ${ }^{1}$, Yizhi Zheng ${ }^{1}$ and \\ Guobao Liu 1,*(D) \\ 1 Guangdong Provincial Key Laboratory for Plant Epigenetics, College of Life Sciences and Oceanography, \\ Shenzhen University, Shenzhen 518060, China; chenly@tsinghua-sz.org (L.C.); sunyajun43@163.com (Y.S.); \\ sunshine@szu.edu.cn (Y.L.); biohjz@szu.edu.cn (J.H.); yzzheng@szu.edu.cn (Y.Z.) \\ 2 The Instrumental Analysis Center of Shenzhen University (Lihu Campus), Shenzhen University, \\ Shenzhen 518060, China; zouyd@szu.edu.cn \\ * Correspondence: liugb@szu.edu.cn; Tel.: +86-755-26558081 \\ + These authors contributed equally to this work.
}

Received: 22 July 2020; Accepted: 1 August 2020; Published: 3 August 2020

check for updates

\begin{abstract}
Late embryogenesis abundant (LEA) group 1 (LEA_1) proteins are intrinsically disordered proteins (IDPs) that play important roles in protecting plants from abiotic stress. Their protective function, at a molecular level, has not yet been fully elucidated, but several studies suggest their involvement in membrane stabilization under stress conditions. In this paper, the soybean LEA_1 protein PM1 and its truncated forms (PM1-N: N-terminal half; PM1-C: C-terminal half) were tested for the ability to protect liposomes against damage induced by freeze-thaw stress. Turbidity measurement and light microscopy showed that full-length PM1 and PM1-N, but not PM1-C, can prevent freeze-thaw-induced aggregation of POPC (1-palmitoyl-2-oleoyl-sn-glycero-3-phosphocholine) liposomes and native thylakoid membranes, isolated from spinach leaves (Spinacia oleracea). Particle size distribution analysis by dynamic light scattering (DLS) further confirmed that PM1 and PM1-N can prevent liposome aggregation during freeze-thaw. Furthermore, PM1 or PM1-N could significantly inhibit membrane fusion of liposomes, but not reduce the leakage of their contents following freezing stress. The results of proteolytic digestion and circular dichroism experiments suggest that PM1 and PM1-N proteins bind mainly on the surface of the POPC liposome. We propose that, through its $\mathrm{N}$-terminal region, PM1 functions as a membrane-stabilizing protein during abiotic stress, and might inhibit membrane fusion and aggregation of vesicles or other endomembrane structures within the plant cell.
\end{abstract}

Keywords: LEA protein; liposome; freeze-thaw; intrinsically disordered; membrane stabilizing protein

\section{Introduction}

Plants have developed various adaptations to maintain normal physiological processes under adverse abiotic stress, such as soil salinity, drought and extreme temperatures. For instance, it has been demonstrated experimentally that late embryogenesis abundant (LEA) proteins are involved in plant tolerance to abiotic stress [1-3]. Based on Pfam domains within their sequences, LEA proteins can be classified into eight subgroups [3]. Most research has focused on the protective functions of the LEA_4, LEA_5 and dehydrin subgroups, generating data on expression profile, cellular localization, and the role of the respective genes and proteins. There is relatively little research on the protective roles of other groups, including the LEA_1 proteins, which are highly expressed in mature seeds and also accumulate in vegetative tissues under stress conditions [4-6]. Some genetic studies have been performed showing that the over-expression of LEA_1 genes, such as LEA4-1 from Brassica napus, BhLEA1 and BhLEA2 
from Boea hygrometrica, AtLEA4-5 from Arabidopsis thaliana, and XsLEA1-8 from Xerophyta schlechteri, confer tolerance to salt, drought and osmotic stress in transgenic plants [5-7]. The over-expression of recombinant Gastrodia elata GeLEA1-1 or Xerophyta schlechteri XsLEA1-8 enhances Escherichia coli viability under low-temperature or heat stress $[7,8]$. In addition, in vitro, the recombinant LEA_1 proteins AtLEA4-2 and AtLEA4-5 (both A. thaliana) and XsLEA1-8 can preserve lactate dehydrogenase activity and prevent this enzyme aggregating during freeze-thaw, heat, desiccation and oxidative stress $[7,9,10]$. Liu et al. suggested that BhLEA1 and BhLEA2 play a general protective role in the plant cell during dehydration stress and increase membrane and protein stability, as indicated by the relatively low electrolyte leakage and higher SOD and POD activity in transgenic plant leaves [5]. In contrast, $A$. thaliana basic protein LEA18 (LEA_1) specifically aggregates and destabilizes negatively charged liposomes, which suggests that LEA18 does not function as a membrane-stabilizing protein, but could modulate membrane stability depending on membrane composition [11].

The LEA proteins are a broad family of proteins, many of which are thought to be intrinsically disordered proteins (IDPs) with "moonlighting" activity [3,10]. However, to our knowledge, relatively few individual LEA proteins have been shown to have multifunctional protective activities. One example of a multifunctional protein, PM1, a LEA_1 protein from soybean, can interact with a range of other molecules, such as non-reducing sugars, poly-L-lysine and phospholipids, during dehydration. PM1 is likely to be an important component of the cellular, organic glass that may stabilize desiccation-sensitive proteins and membranes in stressed plants [12]. PM1 contains a high proportion of basic amino acids, including 13 lysine, 5 arginine and 10 histidine residues, but these are distributed unequally along the length of the protein. There are 12 lysine residues and 3 arginine residues located in the $\mathrm{N}$-terminal half (residues 1-84), while 9 histidine residues and 2 arginine residues are located in the C-terminal region (residues $85-173$ ). In previous papers, we have demonstrated that PM1 protein can bind some metal ions $\left(\mathrm{Fe}^{3+}, \mathrm{Ni}^{2+}, \mathrm{Cu}^{2+}\right.$ and $\left.\mathrm{Zn}^{2+}\right)$ and so play an important protective role in reducing oxidative damage and ion toxicity in plants exposed to abiotic stress [13]. In addition, PM1 or its truncated version, PM1-C (C-terminal half only), but not PM1-N, can form oligomers and high molecular weight (HMW) complexes via its C-terminal histidine residues both in vitro and in planta. Crucially, binding of $\mathrm{Cu}^{2+}$ at high concentrations, which takes place through the same histidine residues, seems to promote oligomerization and the formation of HMW complexes by PM1 [14].

In the present paper, we investigate whether soybean LEA_1 protein PM1 and its two truncated forms, PM1-N and PM1-C, possess the ability to suppress freeze-thaw-induced damage of liposomes. We show that only PM1 and PM1-N can effectively prevent aggregation of POPC liposomes caused by freeze-thaw treatment. Furthermore, we show that, although PM1 and PM1-N inhibit membrane fusion events, they do not reduce leakage of POPC liposomes. On the basis of these observations, we propose that the N-terminal region of PM1 protein has a membrane stabilizing function during abiotic stress.

\section{Results}

\subsection{PM1 and PM1-N Proteins Inhibit the Freeze-Thaw-Induced Increase in Turbidity of a Liposome Suspension}

The cell membrane is composed of lipids (phospholipids and cholesterol), proteins and carbohydrate groups. Among the phospholipids, phosphatidylcholine (PC)represents a major component of biological membranes and the PC, POPC (1-palmitoyl-2-oleoyl-sn-glycero-3-phosphocholine), can be used to produce liposomes that model cell membranes. Light scattering due to aggregation of POPC liposomes can be measured by apparent absorbance at $400 \mathrm{~nm}$ [15]. The $\mathrm{OD}_{400}$ of a freshly prepared POPC liposome suspension was $\sim 0.3$ and the addition of one of the proteins thaumatin, PM1, PM1-N or PM1-C to POPC liposomes did not obviously affect their turbidity before exposure to stress (Figure 1).

The turbidity, as shown by $\mathrm{OD}_{400}$, of the liposome suspension increased markedly to 0.8 after three freeze-thaw cycles, indicating that the freeze-thaw treatment causes liposome aggregation. When $0.8 \mathrm{mg} / \mathrm{mL}$ thaumatin (molar ratio of protein:lipid 1:3300) or $0.8 \mathrm{mg} / \mathrm{mL}$ PM1-C protein (molar ratio of 
protein:lipid 1:1650) was added to the POPC liposome suspension, its $\mathrm{OD}_{400}$ increased to 0.6 after the freeze-thaw treatment, which is significantly different $(p<0.01)$ to that of liposomes only. Thaumatin was chosen as a negative control in the following study because of having no known function in membrane protection [11] and its similar molecular size to PM1 protein. There was no statistical difference in turbidity between liposome/PM1-C and liposome/thaumatin. However, when PM1 or PM1-N protein $(0.04-0.4 \mathrm{mg} / \mathrm{mL})$ was included in the liposome suspension, the turbidity increase after freeze-thaw was appreciably suppressed and the extent of this suppression was dependent on the concentration of the added protein, being significantly $(p<0.05)$ or extremely significantly different $(p<0.01)$ from that of thaumatin. When the concentration of PM1 (molar ratio of protein:lipid 1:3300) or PM1-N protein (molar ratio of protein:lipid $\sim 1: 1650$ ) reached $0.8 \mathrm{mg} / \mathrm{mL}$, the post-treatment turbidity was 0.4 at $\mathrm{OD}_{400}$, i.e., similar to that before freeze-thaw.

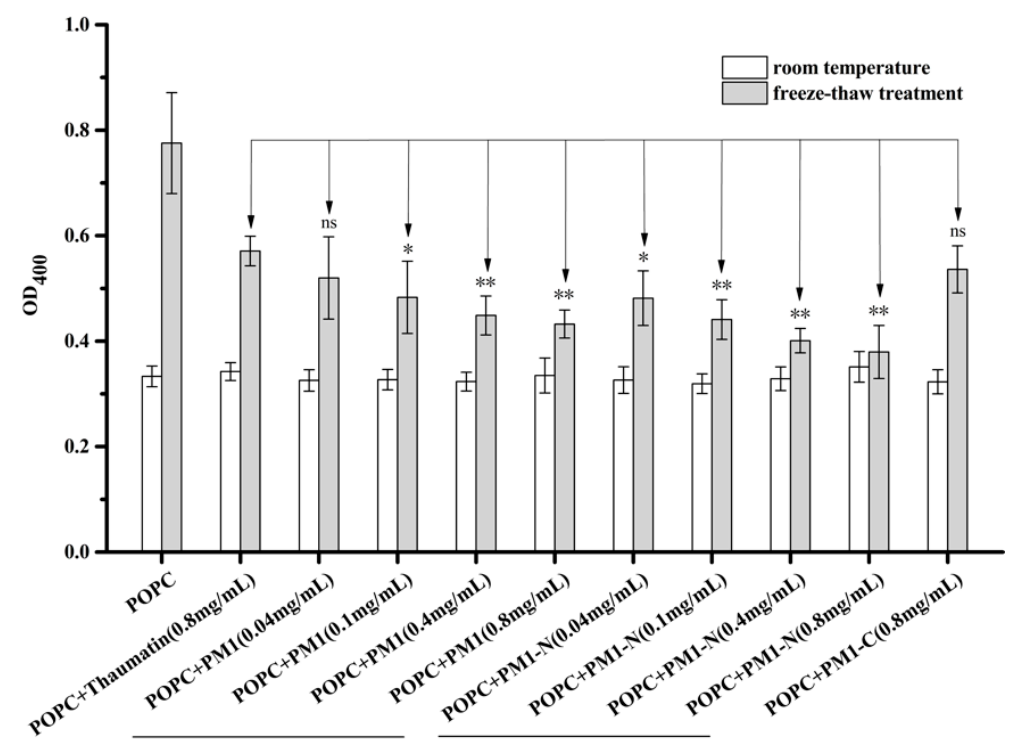

Figure 1. PM1 and its N-terminal region prevent freeze-thaw-induced liposome aggregation. Turbidity of POPC liposomes before and after freeze-thaw treatment in the presence and absence of PM1, PM1-N or PM1-C. For the freeze-thaw test, the samples were frozen in an ethylene glycol bath at $-20^{\circ} \mathrm{C}$ for $2 \mathrm{~h}$ and allowed to thaw for $30 \mathrm{~min}$ at $28^{\circ} \mathrm{C}$. This freeze-thaw cycle was repeated up to three times. ** denotes significance at $p<0.01,{ }^{*}$ denotes $p<0.05$ and "ns" denotes not significant using one-way ANOVA, plus a Tukey post-hoc test.

2.2. PM1 and PM1-N Proteins Can Inhibit or Prevent Freeze-Thaw-Induced Aggregation of Liposomes and Isolated Thylakoid membranes

The inhibitory effect of PM1, PM1-N or PM1-C protein on liposome aggregation can be followed by light microscopy. Before freeze-thaw treatment, POPC liposomes were small in size and evenly distributed in the suspension (Figure 2A). The addition of one of thaumatin, PM1, PM1-N or PM1-C proteins to POPC liposomes did not cause aggregation before freeze-thaw treatment, but in the absence of added proteins, liposome aggregation could be seen to occur after freeze-thaw treatment. With either $0.8 \mathrm{mg} / \mathrm{mL}$ thaumatin (negative control) or $0.8 \mathrm{mg} / \mathrm{mL}$ PM1-C protein in the suspension, the liposomes still aggregated after freeze-thaw. In contrast, when $0.8 \mathrm{mg} / \mathrm{mL}$ PM1 or $0.8 \mathrm{mg} / \mathrm{mL}$ PM1-N protein was added to liposomes, the suspension remained homogeneous even after freeze-thaw.

Next, the anti-aggregation effect of the PM1, PM1-N or PM1-C proteins on natural biological material was tested using thylakoid membranes isolated from spinach leaves (Spinacia oleracea). Under the light microscope, the thylakoid membranes appeared as evenly distributed, small particles in suspension (Figure 2B). The addition of thaumatin, PM1, PM1-N or PM1-C proteins individually to thylakoid membranes did not cause aggregation. However, after freeze-thaw treatment, the thylakoid membranes aggregated markedly, as was apparent by light microscopy, and even being directly visible 
to the naked eye. The addition of $0.8 \mathrm{mg} / \mathrm{mL}$ thaumatin (negative control) or $0.8 \mathrm{mg} / \mathrm{mL}$ PM1-C protein did not prevent the formation of thylakoid aggregates when the suspension was subjected to freeze-thaw. In contrast, when $0.8 \mathrm{mg} / \mathrm{mL}$ PM1 or $0.8 \mathrm{mg} / \mathrm{mL}$ PM1-N protein was added to the thylakoid suspension, there was almost no aggregation after freeze-thaw.

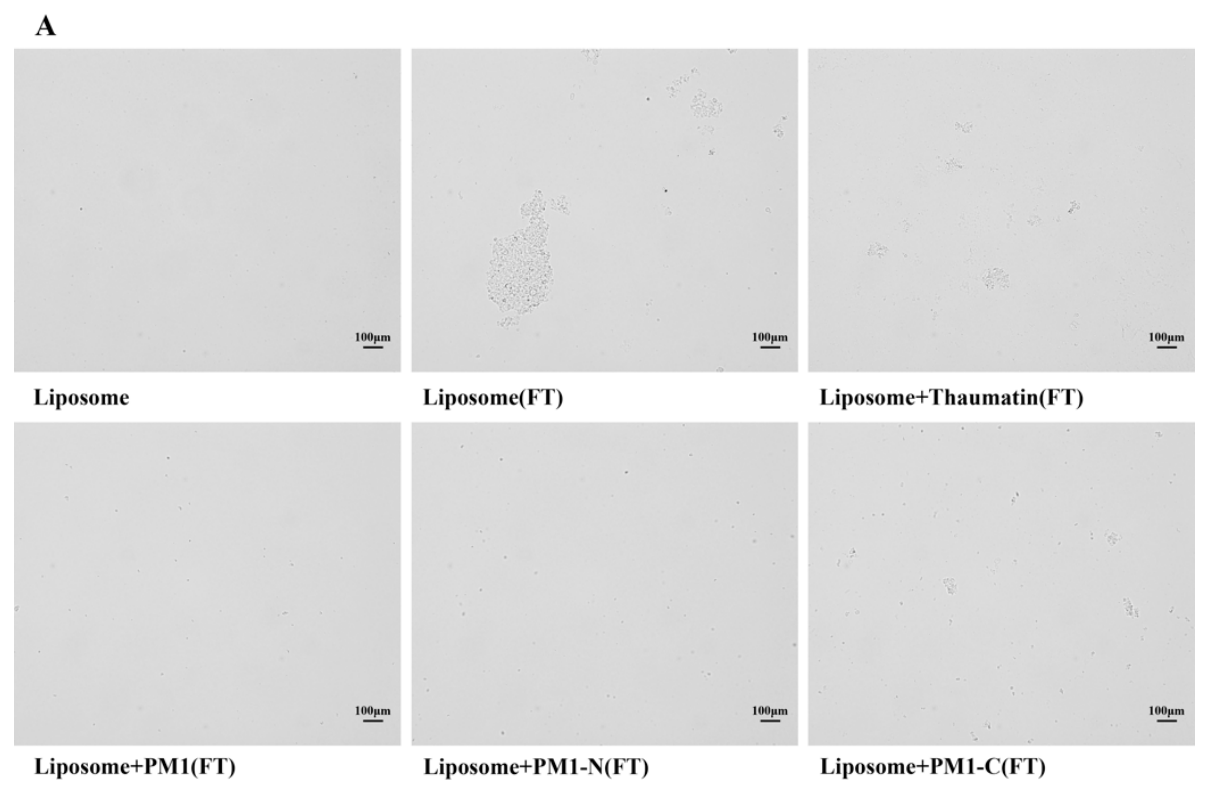

B

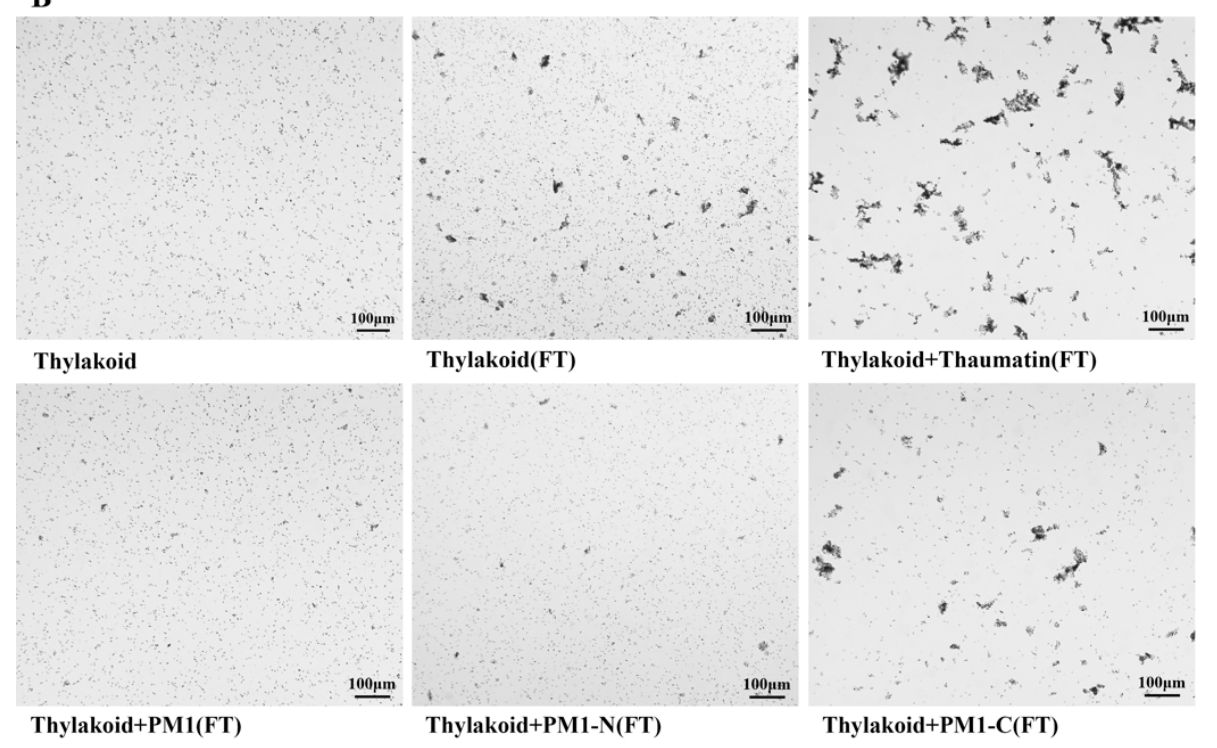

Figure 2. PM1 and its N-terminal region prevent POPC liposome or thylakoid aggregation resulting from freeze-thaw treatment as assessed by light microscopy. (A) POPC liposomes; (B) spinach leaf thylakoids. Bars in (A) and (B) represent $100 \mu \mathrm{m}$. FT: freeze-thaw treatment.

\subsection{The Addition of Either PM1 or PM1-N Protein Can Stabilize the Liposome Particle Size}

The particle size distribution of POPC liposomes was measured and a single peak was obtained by dynamic light scattering (DLS) centering around $130 \mathrm{~nm}$ before freeze-thaw treatment (Figure 3). The addition of thaumatin, PM1, PM1-N or PM1-C individually to liposomes did not affect the particle size distribution (Figure 3A). After freeze-thaw treatment, another peak of $800 \mathrm{~nm}$ was observed besides the main peak of $130 \mathrm{~nm}$, indicating that freeze-thaw can cause liposome adhesion, involving liposome fusion and/or aggregation. When either $0.8 \mathrm{mg} / \mathrm{mL}$ thaumatin or $0.8 \mathrm{mg} / \mathrm{mL}$ PM1-C protein 
was added to the liposome suspension, a peak at 250-270 nm was present besides the main peak of $130 \mathrm{~nm}$. In contrast, when either $0.8 \mathrm{mg} / \mathrm{mL}$ PM1 or $0.8 \mathrm{mg} / \mathrm{mL}$ PM1-N protein was added to the liposome suspension, a small peak of particle size $\sim 50 \mathrm{~nm}$ emerged besides the main peak of $140 \mathrm{~nm}$ (Figure 3B).
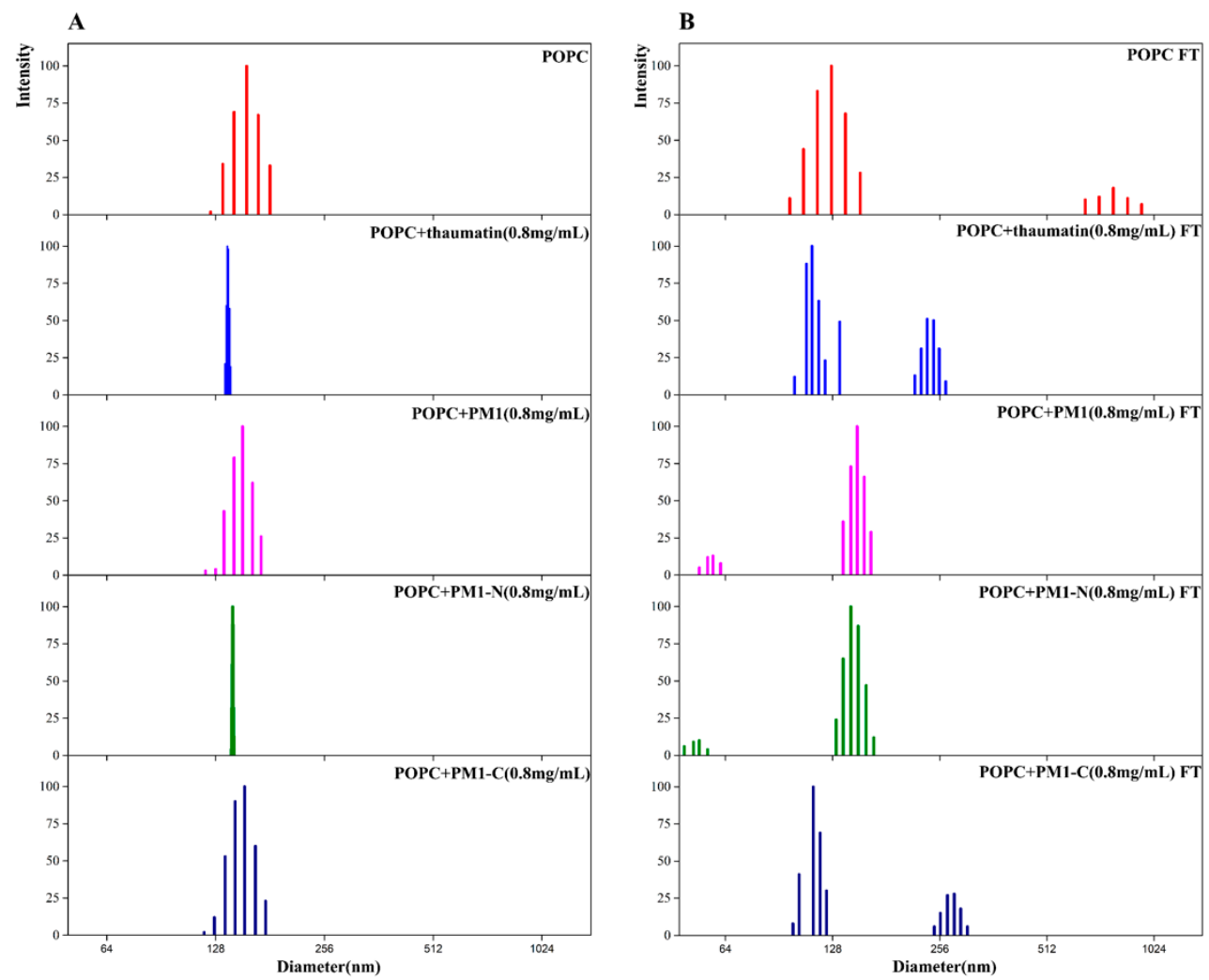

Figure 3. Size distribution of POPC liposomes before and after freeze-thaw treatment in the presence and absence of PM1, PM1-N or PM1-C. (A) Size distribution of POPC liposomes before treatment; (B) size distribution of POPC liposomes after freeze-thaw treatment.

Together, the above results suggest that PM1 and PM1-N, but not PM1-C, can inhibit aggregation of liposomes and thylakoids caused by freeze-thaw treatment; the effect was concentration-dependent within a certain range and also specific. Furthermore, PM1 and PM1-N protein can prevent membrane fusion in POPC liposomes due to freeze-thaw.

\subsection{PM1 and PM1-N Proteins Cannot Prevent Freeze-Thaw-Induced Leakage of Liposomes}

Freeze-thaw treatment can cause the collapse of liposome membranes, causing leakage of liposome contents. To obtain a deeper insight into the protective effects of PM1 protein and its N-terminal region, a leakage experiment, using the fluorescent probe, carboxyfluorescein (CF), trapped within liposomes, was carried out according to [16]. As shown in Figure 4, the leakage rate of pure POPC liposomes after freeze-thaw treatment was $91.9 \%$, suggesting that freeze-thaw almost entirely destroys their integrity. In the presence of the proteins (all at $0.8 \mathrm{mg} / \mathrm{mL}$ ) used in this study, the post-treatment leakage rates of POPC liposomes were as follows: thaumatin, 86.8\%; PM1, 80.1\%; PM1-N, 80.5\%; PM1-C, $79.6 \%$. There was no statistical difference in CF leakage rates between any of the liposome/protein combinations and the liposome-only samples, suggesting that PM1 and its truncated versions prevent leakage no better than thaumatin or, indeed, no protein (Figure 4). 


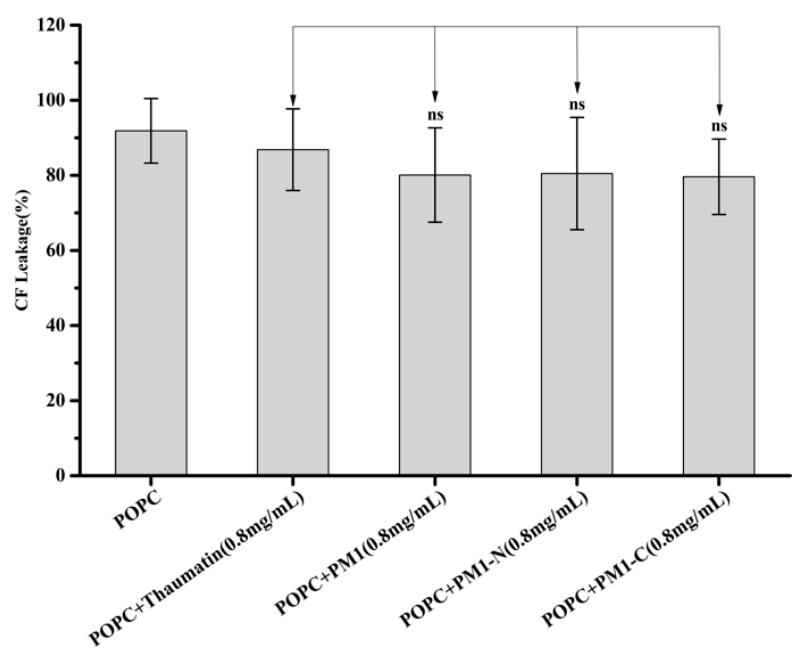

Figure 4. Influence of PM1, PM1-N and PM1-C on CF leakage from liposomes after freeze-thaw treatment. POPC liposomes were subjected to freeze-thaw in the absence or presence of PM1, PM1-N or PM1-C, or thaumatin as a negative control protein. "ns" denotes not significant using one-way ANOVA, plus a Tukey post-hoc test.

\subsection{PM1 and PM1-N Proteins Can Effectively Inhibit or Prevent Membrane Fusion}

The leakage of soluble contents from liposomes is often accompanied by membrane fusion [17]. The degree of fusion of the membrane can be assessed quantitatively by fluorescence resonance energy transfer (FRET) [18]. In the present paper, POPC liposomes whose membranes contained a pair of fluorescently labeled phospholipids (Rh-PE and NBD-PE) that can undergo FRET were mixed with unlabeled liposomes. When membrane fusion between labeled and unlabeled liposomes occurs, the degree of FRET between Rh-PE and NBD-PE will be reduced, due to dilution of the fluorescent probes. As shown as Figure 5, about $41.6 \%$ of liposomes underwent membrane fusion after freeze-thaw. When $0.8 \mathrm{mg} / \mathrm{mL}$ thaumatin was added to the liposome suspension, the degree of membrane fusion was $37.1 \%$ after freeze-thaw is not significantly different from that of liposomes only. When $0.8 \mathrm{mg} / \mathrm{mL}$ PM1-C protein was added to the liposome suspension, the degree of membrane fusion was $31.7 \%$ after freeze-thaw, showing a significant difference $(p<0.05)$ with liposomes only or thaumatin as negative control. However, in the presence of $0.8 \mathrm{mg} / \mathrm{mL}$ PM1 or $0.8 \mathrm{mg} / \mathrm{mL}$ PM1-N, the degree of membrane fusion reduced markedly to $10.6 \%$ or $8.6 \%$, respectively, showing significant differences $(p<0.01)$ to liposomes only or thaumatin as negative control. Thus, the ability of PM1 to reduce membrane fusion in POPC liposomes caused by freeze-thaw largely resides in its $\mathrm{N}$-terminal sequence.

The above results show that PM1 or PM1-N protein do not reduce the leakage of CF from POPC liposomes subjected to freeze-thaw, although they can significantly inhibit membrane fusion. Compared to thaumatin protein as negative control, on the other hand, PM1-C protein did not reduce leakage, and only reduced membrane fusion of POPC liposomes to some extent.

\subsection{The Presence of POPC Liposomes Does Not Affect Digestion of PM1 by Trypsin}

PM1 is an IDP, a group of proteins that are on the whole degraded 100 times faster than folded proteins [19]. Liposomes can increase the folding of IDPs, and this can be measured by a limited proteolysis test $[20,21]$. Trypsin is a Lys-specific protease that can recognize the Lys residues located exclusively within the N-terminal half of the soybean PM1 sequence. Besides the main band at $20 \mathrm{kDa}$, the purified PM1 protein contains several smaller bands, which also can be detected by PM1 specific antibody [14], probably indicating a small amount of degradation in protein preparation. Figure 6A shows that PM1 was readily and gradually degraded by trypsin over $30 \mathrm{~min}$, as indicated by the main band at $\sim 20 \mathrm{kDa}$ becoming weaker and by the appearance of smaller bands below $17 \mathrm{kDa}$. This pattern 
of degradation did not change in the presence of POPC liposomes, suggesting that the structure of PM1 protein remains disordered state and is not influenced by the presence of liposomes.

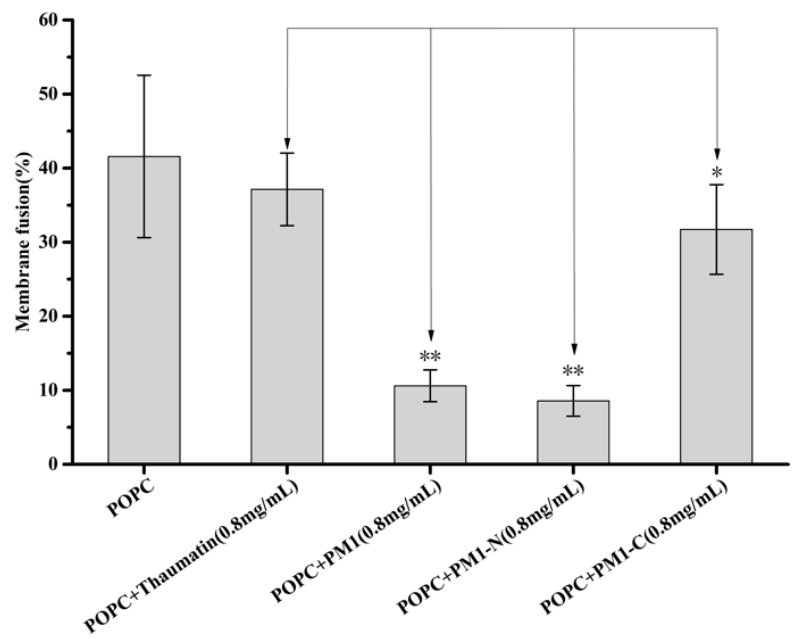

Figure 5. Effect of PM1, PM1-N and PM1-C on membrane fusion caused by freeze-thaw treatment. POPC liposomes were subjected to freeze-thaw in the absence or presence of PM1, PM1-N or PM1-C, or thaumatin as a negative control protein. Membrane fusion was determined by a FRET assay. ** denotes significance at $p<0.01$ and * denotes $p<0.05$ using one-way ANOVA, plus a Tukey post-hoc test.

A

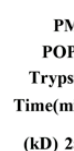

M

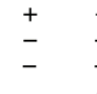

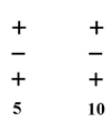
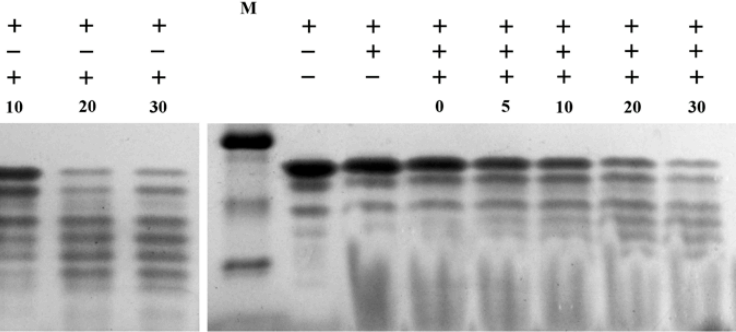

B

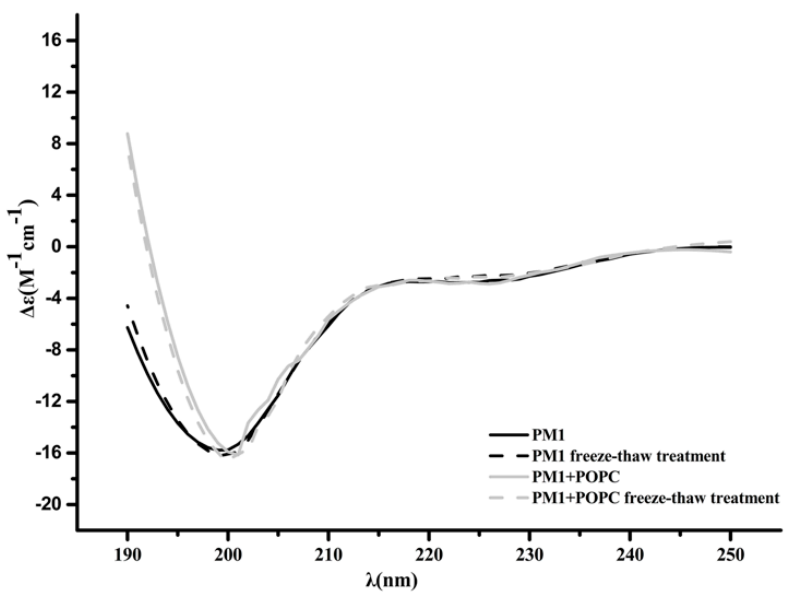

Figure 6. PM1 does not gain structure in the presence of liposomes. (A) Digestion of PM1 by trypsin in the presence or absence of POPC liposomes. (B) CD spectra of PM1 alone and PM1 in the presence of liposomes before and after freeze-thaw treatment.

\subsection{The Presence of POPC Liposomes Does Not Change the Secondary Structure of PM1 Protein}

It has been reported that Zea mays dehydrin DHN1 and A. thaliana dehydrin Lti30 bind the negatively charged head groups of phospholipids and that this is accompanied by an increase 
in $\alpha$-helicity of both LEA proteins $[15,22-24]$. We tested the effect of POPC liposomes on PM1 secondary structure using circular dichroism (CD) (Figure 6B). We observed that PM1 protein remained unstructured both before, and after, freeze-thaw in the absence or presence of liposomes, as indicated by an ellipticity minimum at $198 \mathrm{~nm}$.

Together, the results of trypsin digestion and CD analysis suggest that PM1 interacts mainly with the surface of the uncharged POPC liposomes.

\section{Discussion}

LEA proteins, a large and highly diverse protein family, accumulate during seed desiccation in the later stages of embryogenesis. Given the diversity and compartmentalization of LEA proteins in plant tissues, a detailed understanding of their function involves characterization of each protein individually. The over-expression of some LEA protein genes in transgenic plants confers tolerance to low-temperature stress. For example, over-expression of $A$. thaliana COR15A and COR15B (LEA_4) in Arabidopsis or of Citrus unshiu CuCOR19 (dehydrin) in tobacco (Nicotiana tabacum) increases the freezing tolerance of the resulting transgenic plants, as indicated by reduced electrolyte leakage compared to controls [25-27]. In vitro, COR15A and COR15B stabilize liposomes, either in terms of freeze-induced solute leakage or membrane fusion [26]. Similarly, Pisum sativum LEAM (LEA_4) or the Artemia franciscana AfrLEA2 and AfrLEA3m (LEA_4) increase liposome stability after freeze-thawing, as illustrated by a reduced leakage of entrapped CF molecules [28,29]. In contrast, three $A$. thaliana LEA proteins, LEA1, LEA26 and LEA27 (LEA_2), increase CF leakage from liposomes after freeze-thaw treatment [16]. Arabidopsis Lti30 (dehydrin) assembles lipid vesicles and native thylakoid membranes into aggregates by a possible role in membrane cross-linking [15], while Arabidopsis LEA18 protein (LEA_1) increases CF leakage, liposome membrane fusion and liposome aggregation under non-freezing conditions [11].

Shih et al. reported that soybean PM1 protein can interact with POPC lipids to maintain the liquid-crystal phase over a wide temperature range in the dry state [12]. In the present paper, we found that at high concentrations PM1/PM1-N protein specifically binds to or interacts with the surface of liposome membranes in solution and in the frozen state. For this reason, we speculate that, in a solution of PM1 or PM1-N, the liposomes are kept separate from each other by the protein molecules. During freeze-thaw, liposomes break down or fragment such that their contents (CF in our experiments) leak out [26]. In the absence of PM1 and PM1-N proteins, the resulting membrane fragments can fuse and POPC liposomes aggregate to such an extent that they become visible under the light microscope and even to the naked eye. In the presence of PM1 and PM1-N, the adherence of liposome membranes was reduced and membrane fusion and liposome aggregation was reduced, even though leakage of CF contents was not prevented. Therefore, our observations support a protection mechanism for PM1 on cells and cell membranes that is very similar to the "molecular shield" model. This model was proposed by Wise and Tunnacliffe to explain the protective function of LEA proteins towards other proteins under water stress conditions [30].

Some dehydrins, such as Zea mays DHN1, Thellungiella salsuginea TsDHN1 and TsDHN2, and A. thaliana ERD14 and Lti30, bind phospholipids in vitro $[15,19,22,23,31]$. These interactions between dehydrins and phospholipid molecules are driven by electrostatics and depend on the positively charged residues in the characteristic lysine-rich K-segment of the dehydrins, which pair with the negatively charged head groups of the lipids [24]. Ananlysis of the amino acid composition of soybean basic PM1 protein shows that the N-terminal is also rich in lysine residues and has +6 positively charged amino acids in solution at $\mathrm{pH}$ 7.4. It is reasonable to speculate that the $\mathrm{N}$-terminal region of PM1 might interact with the surface of liposomes, especially with the negatively charged head groups of phospholipid molecules.

On the other hand, the C-terminal region of PM1 contains 9 histidine residues and has only +1 positively charged amino acids at $\mathrm{pH}$ 7.4. In contrast to the PM1 and PM1-N proteins, PM1-C cannot effectively prevent liposome aggregation and membrane fusion during freeze-thaw. This could be 
because PM1-C, with many fewer charged residues, can only attach to the liposome surface with low affinity. Therefore, it is not as effective at keeping liposomes separate and consequently preventing them from aggregating. Therefore, the anti-aggregation function of PM1 protein on cell membranes is likely mainly conferred by its $\mathrm{N}$-terminal region.

A. thaliana basic LEA18 protein and soybean PM1 protein both belong to the LEA_1 subgroup of LEA proteins. However, there is only $30 \%$ similarity between the two protein sequences. Intriguingly, LEA18 does not function as a membrane-stabilizing protein, in contrast to PM1. Instead, the LEA18 protein causes aggregation and destabilization of negatively charged liposomes [11].

We have carried out a series of studies on the protective functions of soybean PM1 protein. The amino acid sequence shows that its histidine residues are mainly located in the C-terminal half, while its lysine residues are mostly in the N-terminal region. The C-terminal region has the potential to bind metal ions, scavenge hydroxyl radicals, and form oligomers and HMW complexes. These functions are directly related to the number of histidine residues in the C-terminal region $[13,14]$. In contrast to the disordered nature of the C-terminus, the highly conserved N-terminal half of PM1 can be induced to form significant levels of $\alpha$-helical structure by SDS or trifluoroethanol [14]. At the same time, this N-terminal region of PM1 has a protective effect on LDH activity (Figure A1) and can also effectively prevent liposome aggregation. Both these functions may relate to the number of lysine residues in the N-terminal region. It has been speculated that the two halves of PM1 could perform different functions by binding different targets. The conformational flexibility and structural plasticity of PM1, as an IDP, may be the molecular basis for its multiple protective functions.

\section{Materials and Methods}

\subsection{Protein Over-Expression and Purification}

Immature soybean (G. max L. Merr. cv Bainong 6\#) seeds were collected from pods 35-45 d after flowering and then total RNA was extracted from plant material with Trizol reagent (TAKARA, Otsu, Japan). The full-length ORF of the PM1 gene was amplified by RT-PCR using the PrimeScript ${ }^{\mathrm{TM}}$ one-step RT-PCR kit (TAKARA, Otsu, Japan). Constructs containing the full-length soybean PM1, PM1-N and PM1-C sequences were described previously [13,14]. Recombinant PM1, PM1-N and PM1-C proteins were purified using affinity chromatography, and His-tags were removed by incubation with thrombin as previously described [14]. The proteins were lyophilized and then stored at $-80^{\circ} \mathrm{C}$ for later use. The proteins were resuspended in a suitable buffer before use.

\subsection{Preparation of Liposomes}

POPC (1-palmitoyl-2-oleoyl-sn-glycero-3-phosphocholine) was obtained from Avanti Polar Lipids (Alabaster, AL, USA). Large unilaminar vesicles (LUVs, $100 \mathrm{~nm}$ ) of POPC were prepared by the extrusion method described previously [15]. Briefly, the lipids were dissolved in chloroform, and lipid mixtures were dried under a gentle liquid nitrogen flow and subsequently rehydrated in $10 \mathrm{mM}$ $\mathrm{Na}_{2} \mathrm{HPO}_{4}-\mathrm{KH}_{2} \mathrm{PO}_{4}$ buffer, $\mathrm{pH} 7.4$. The lipid solution was extruded in an Avanti Mini Extruder $(100 \mathrm{~nm}$ polycarbonate filter), repeated 15 times and then liposomes were collected.

For the leakage experiment, liposomes were made according to [16]. Briefly, an appropriate amount of POPC lipid was hydrated in buffer $(250 \mu \mathrm{L} 100 \mathrm{mM} \mathrm{CF}$ (carboxyfluorescein) in $10 \mathrm{mM}$ $\mathrm{Na}_{2} \mathrm{HPO}_{4}-\mathrm{KH}_{2} \mathrm{PO}_{4}$ buffer, $\mathrm{pH}$ 7.4). The lipid solution was extruded as above and liposomes were collected. To remove external CF, the lipid samples were passed through a Sephadex G-25 column (NAP-5, GE Healthcare, Milwaukee, WI, USA) in buffer (10 mM Na $2 \mathrm{HPO}_{4}-\mathrm{KH}_{2} \mathrm{PO}_{4}, 0.1 \mathrm{mM}$ EDTA and $50 \mathrm{mM} \mathrm{NaCl}$ ).

To measure membrane fusion, two liposome samples were prepared: One containing $1 \mathrm{~mol} \%$ of both NBD-PE and Rh-PE, while the other contained only unlabeled lipids. After extrusion, the two samples were mixed at a 1:9 (labeled:unlabeled) ratio. All liposomes were diluted to $20 \mathrm{mg} / \mathrm{mL}$ before use. 


\subsection{Thylakoid Membrane Preparation}

Thylakoids were isolated from spinach (Spinacia oleracea) as previously described [32]. Briefly, $40 \mathrm{~g}$ spinach leaves and $100 \mathrm{~mL}$ cold A buffer (0.3 M Suc, $50 \mathrm{mM}$ Na-phosphate, pH 7.4, and $5 \mathrm{mM}$ $\mathrm{MgCl}_{2}$ ) was mixed for $5 \times 10 \mathrm{~s}$ with a coldmixer. The solution was filtered with $50 \mu \mathrm{M}$ nylon mesh and centrifuged at $3000 \mathrm{rpm}$ for $3 \mathrm{~min}$. The pellet was suspended in $30 \mathrm{~mL}$ A buffer and centrifuged at $4500 \mathrm{rpm}$ for $5 \mathrm{~min}$. The solution was homogenized in $30 \mathrm{~mL} \mathrm{~B}$ buffer $(10 \mathrm{mM}$ phosphate, $\mathrm{pH} 7.4$, $5 \mathrm{mM} \mathrm{MgCl}_{2}$, and $5 \mathrm{mM} \mathrm{NaCl}$ ) and centrifuged at $4500 \mathrm{rpm}$ for $5 \mathrm{~min}$. The pellet (about $200 \mathrm{mg}$ ) was homogenized in $10 \mathrm{~mL}$ buffer (0.1 M Suc, $10 \mathrm{mM}$ phosphate, $\mathrm{pH}$ 7.4, $5 \mathrm{mM} \mathrm{MgCl}_{2}$ and $\left.5 \mathrm{mM} \mathrm{NaCl}\right)$.

\subsection{Freeze-Thaw Treatment of Liposomes}

Either liposomes $(20 \mathrm{mg} / \mathrm{mL}$ ) or thylakoid membranes (about $20 \mathrm{mg} / \mathrm{mL}$ ) were mixed with the same volume of the PM1, PM1-N and PM1-C proteins at concentrations of $0.08,0.2,0.8$ or $1.6 \mathrm{mg} / \mathrm{mL}$ or the negative control protein thaumatin (from Thaumatococcus daniellii; Sigma, St. Louis, MO, USA) at a concentration of $1.6 \mathrm{mg} / \mathrm{mL}$ in $10 \mathrm{mM} \mathrm{Na} \mathrm{HPO}_{4}-\mathrm{KH}_{2} \mathrm{PO}_{4}$ buffer, $\mathrm{pH} 7.4$, or with buffer alone. The freeze-thaw treatment was performed as previously described [26]; samples were then frozen in an ethylene glycol bath at $-20^{\circ} \mathrm{C}$ for $2 \mathrm{~h}$ and allowed to thaw for $30 \mathrm{~min}$ at $28^{\circ} \mathrm{C}$. This freeze-thaw cycle was repeated up to three times.

\subsection{Turbidity Measurement and Dynamic Light Scattering (DLS)}

A simple aggregation assay was performed by measuring apparent absorbance [33], namely turbidity, due to light scattering at $400 \mathrm{~nm}$ (denoted as $\mathrm{OD}_{400}$ ), with an Ultro Spec 2000 (GE Healthcare, Milwaukee, WI, USA). In addition, particle size distribution in suspension was measured using a DLS analyzer (Zetaplus Zeta Potential Analyzer, Brookhaven Instruments, Holtsville, NY, USA) [11]. For both of these measurements, the samples were diluted to avoid saturation.

\subsection{Light Microscopy}

For light microscopy, $6 \mu \mathrm{L}$ samples were placed on a glass slide, and images were examined using the optical microscope Olympus BX51 (Olympus Corporation, Tokyo, Japan).

\subsection{CF Leakage Experiments}

The leakage experiments were performed as previously reported [16]. Same of $12 \mu \mathrm{L}$ were diluted with $300 \mu \mathrm{L} \mathrm{Na}{ }_{2} \mathrm{HPO}_{4}-\mathrm{KH}_{2} \mathrm{PO}_{4}$ buffer in 96-well plates. CF fluorescence was measured with a Varioskan Flash multimode reader(Thermo Scientific, Waltham, MA, USA) with the following settings: Excitation $444 \mathrm{~nm}$; emission $555 \mathrm{~nm}$. While fluorescence is strongly quenched at the high concentration inside intact liposomes, fluorescence will increase when CF is released into the surrounding buffer. The $100 \%$ fluorescence level for leakage(i.e., complete release of entrapped CF) was obtained by detergent lysis of the liposomes with $5 \mu \mathrm{L} 0.1 \%$ Triton X-100 solution.

\subsection{Membrane Fusion Measurements}

Membrane fusion was measured as a reduction of fluorescence resonance energy transfer (FRET) between Rh-PE and NBD-PE by measuring the increase in NBD fluorescence, due to the dilution of the probes after fusion of labeled, and unlabeled, liposome samples [18]. This is using a Hitachi F-4500 fluorescence instrument (Hitachi, Tokyo, Japan) at an excitation wavelength of $450 \mathrm{~nm}$ and an emission wavelength of $530 \mathrm{~nm}$. The $100 \%$ fusion level (i.e., maximal NBD fluorescence in each sample) was determined after lysis of the liposomes with Triton X-100 solution.

\subsection{Limited Proteolysis}

Protease sensitivity was tested with trypsin [15]. Typically, PM1 $(1 \mathrm{mg} / \mathrm{mL})$ was mixed with the same volume of liposomes $(1 \mathrm{mg} / \mathrm{mL})$. To start the digestion, trypsin was added at a mass ratio of 1:200, 
trypsin to PM1. After the samples were incubated at room temperature for $0-30 \mathrm{~min}$, the reactions were terminated by adding $1 \mathrm{mM}$ phenylmethanesulfonyl fluorid, a trypsin inhibitor. All samples were mixed with $5 \times$ loading buffer, heated at $95{ }^{\circ} \mathrm{C}$ for $5 \mathrm{~min}$ and then run on a $15 \%$ ready-made SDS-PAGE gel.

\subsection{Far UV-Circular Dichroism Spectroscopy}

PM1 protein $(20 \mu \mathrm{M})$ was mixed with the same volume of liposomes $(2 \mathrm{mg} / \mathrm{mL})$ or with pure buffer with or without freeze-thaw treatment. Far UV-circular dichroism (CD) spectra were recorded using a Jasco J-815 CD spectropolarimeter (JASCO Analytical Instruments, Tokyo, Japan). The acquisition parameters were $0.5 \mathrm{~nm}$ resolution, $1.0 \mathrm{~nm}$ bandwidth, $0.5 \mathrm{~s}$ response and $250-190 \mathrm{~nm}$ wavelength range. Three spectra were averaged and smoothed to reduce noise.

\subsection{In Vitro Lactate Dehydrogenase Assays}

Lactate dehydrogenase (LDH) assays were adapted from [34]. In short, LDH from rabbit muscle (Roche, Mannheim, Germany) was diluted in $100 \mathrm{mM}$ sodium phosphate buffer (pH 7.0) to a final concentration of $0.357 \mu \mathrm{M}$. PM1, PM1-N and PM1-C proteins or the negative control protein lysozyme were added to equal volumes of LDH at molar ratios of 1:1 (test protein: LDH). The enzyme with and without added proteins was frozen in an ethylene glycol bath at $-20^{\circ} \mathrm{C}$ for $2 \mathrm{~h}$ and allowed to thaw for $30 \mathrm{~min}$ at $28^{\circ} \mathrm{C}$. This freeze-thaw cycle was repeated up to five times. The activity of LDH was assayed according to [34].

\subsection{Statistics}

p-Value was determined using SPSS 9 software (SPSS, Inc., Chicago, IL, USA). One-way ANOVA and Tukey post hoc test using InStat3 (GraphPad Software, San Diego, CA, USA) were performed for all the experiments. All experiments were performed at least in triplicate.

Author Contributions: G.L. and Y.Z. (Yizhi Zheng) designed the project. L.C. performed most of the experiments, and Y.S. participated in the experiments. Y.Z. (Yongdong Zou) and J.H. analyzed the leakage experiments and the FRET data. L.C. and Y.S. wrote the draft of the manuscript, J.H., Y.Z. (Yizhi Zheng) and G.L. revised the draft. Funding acquisition and project administration were done by Y.L., Y.Z. (Yizhi Zheng) and G.L. All authors have read and approved the submitted vision of the manuscript.

Funding: This research was funded by National Nature Science Foundation of China (Grant No. 31370289 and 31600203) and Shenzhen Fundamental Research fund (Grant No.JCYJ20170818142241972).

Acknowledgments: We thank the Instrumental Analysis Center of Shenzhen University (Lihu Campus) for providing research instruments.

Conflicts of Interest: The authors declare no conflict of interest.

\section{Abbreviations}

$\begin{array}{ll}\text { LEA } & \text { late embryogenesis abundant } \\ \text { IDP } & \text { intrinsically disordered protein } \\ \text { DLS } & \text { dynamic light scattering } \\ \text { PC } & \text { phosphatidylcholine } \\ \text { POPC } & \text { 1-palmitoyl-2-oleoyl-sn-glycero-3-phosphocholine } \\ \text { CF } & \text { carboxyfluorescein } \\ \text { HMW } & \text { high molecular weight } \\ \text { LUV } & \text { large unilaminar vesicle } \\ \text { FRET } & \text { fluorescence resonance energy transfer } \\ \text { CD } & \text { circular dichroism } \\ \text { LDH } & \text { lactate dehydrogenase }\end{array}$




\section{Appendix A}

To validate whether PM1 could protect cellular proteins under stress conditions, we analyzed the protective effects of PM1, PM1-N or PM1-C protein on LDH during freeze-thaw cycles. Figure A1. shows that, PM1 and PM1-N, but not PM1-C gave a significantly better protection of LDH against freeze-thaw-induced inactivation $(p<0.01)$.

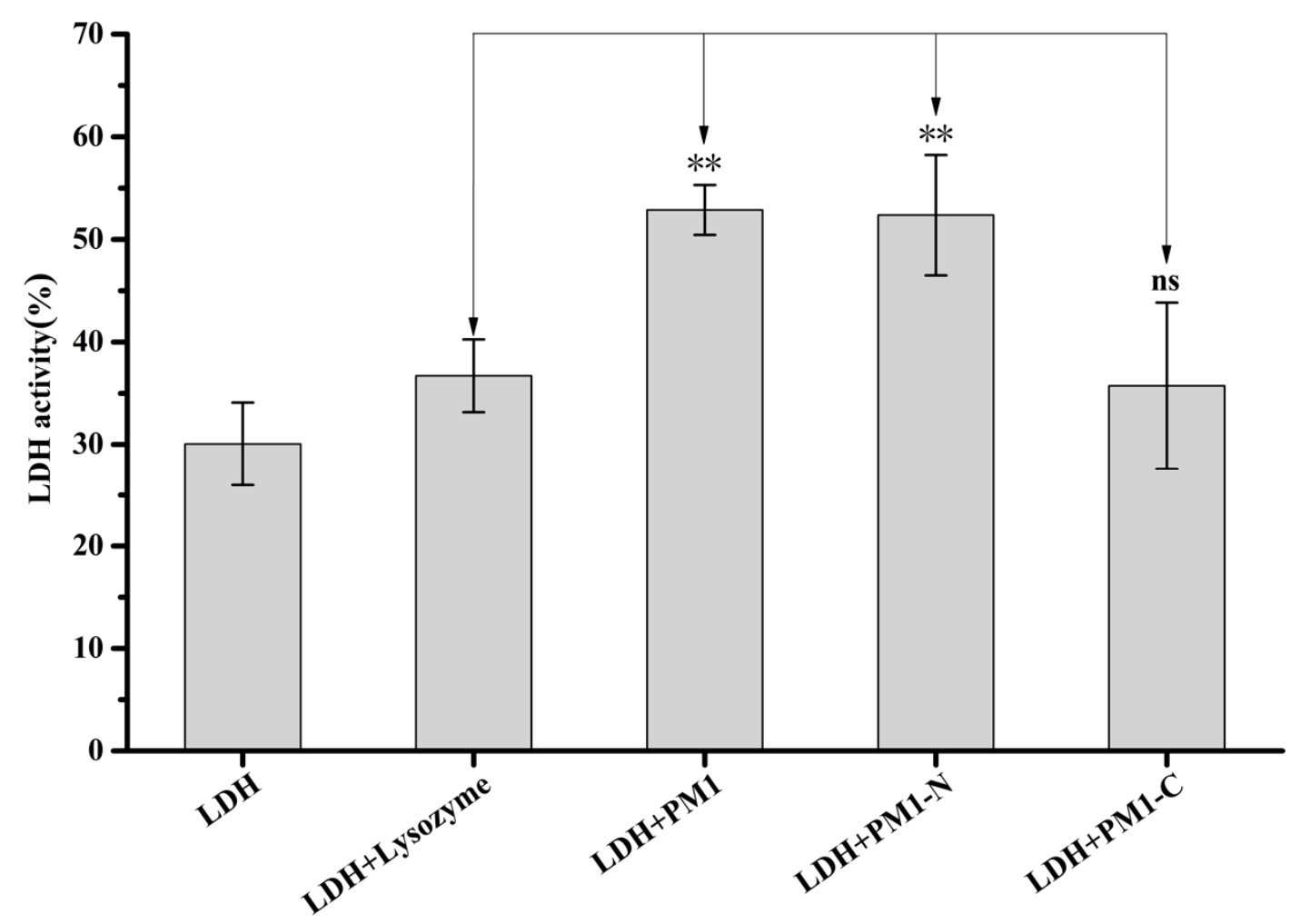

Figure A1. Protective effect of PM1, PM1-N and PM1-C on LDH. LDH was subjected to freeze-thaw in the absence or presence of PM1, PM1-N or PM1-C, or lysozyme as a negative control protein. The samples were frozen in an ethylene glycol bath at $-20^{\circ} \mathrm{Cfor} 2 \mathrm{~h}$ and allowed to thaw for $30 \mathrm{~min}$ at $28^{\circ} \mathrm{C}$. This freeze-thaw cycle wasrepeated up to five times. ${ }^{* *}$ denotes significance at $p<0.01$ and "ns" denotes not significant using one-way ANOVA, plus a Tukey post-hoc test.

\section{References}

1. Tunnacliffe, A.; Wise, M.J. The continuing conundrum of the LEA proteins. Naturwissenschaften 2007, 94, 791-812. [CrossRef] [PubMed]

2. Battaglia, M.; Covarrubias, A.A. Late Embryogenesis Abundant (LEA) proteins in legumes. Front. Plant Sci. 2013, 4, 190. [CrossRef] [PubMed]

3. Artur, M.A.S.; Zhao, T.; Ligterink, W.; Schranz, E.; Hilhorst, H.W.M. Dissecting the Genomic Diversification of Late Embryogenesis Abundant (LEA) Protein Gene Families in Plants. Genome Biol. Evol. 2019, 11, 459-471. [CrossRef] [PubMed]

4. Roberts, J.K.; DeSimone, N.A.; Lingle, W.L.; Dure, L., 3rd. Cellular Concentrations and Uniformity of Cell-Type Accumulation of Two Lea Proteins in Cotton Embryos. Plant Cell 1993, 5, 769-780. [CrossRef] [PubMed]

5. Liu, X.; Wang, Z.; Wang, L.; Wu, R.; Phillips, J.; Deng, X. LEA 4 group genes from the resurrection plant Boeahygrometrica confer dehydration tolerance in transgenic tobacco. Plant Sci. 2009, 176, 90-98. [CrossRef]

6. Olvera-Carrillo, Y.; Campos, F.; Reyes, J.L.; Garciarrubio, A.; Covarrubias, A.A. Functional Analysis of the Group 4 Late Embryogenesis Abundant proteins reveals their relevance in the adaptive response during water deficit in Arabidopsis thaliana. Plant Physiol. 2010, 154, 373-390. [CrossRef] 
7. Artur, M.A.S.; Rienstra, J.; Dennis, T.J.; Farrant, J.M.; Ligterink, W.; Hilhorst, H. Structural Plasticity of Intrinsically Disordered LEA Proteins from Xerophytaschlechteri Provides Protection In Vitro and In Vivo. Front. Plant Sci. 2019, 10, 1272. [CrossRef]

8. Zeng, X.; Ling, H.; Yang, J.; Li, Y.; Guo, S. LEA proteins from Gastrodiaelata enhance tolerance to low temperature stress in Escherichia coli. Gene 2018, 646, 136-142. [CrossRef]

9. Reyes, J.L.; Campos, F.; Wei, H.; Arora, R.; Yang, Y.; Karlson, D.T.; Covarrubias, A.A. Functional dissection of hydrophilins during in vitro freeze protection. Plant Cell Environ. 2008, 31, 1781-1790. [CrossRef]

10. Cuevas-Velazquez, C.L.; Saab-Rincon, G.; Reyes, J.L.; Covarrubias, A.A. The Unstructured N-terminal Region of Arabidopsis Group 4 Late Embryogenesis Abundant (LEA) Proteins Is Required for Folding and for Chaperone-like Activity under Water Deficit. J. Biol. Chem. 2016, 291, 10893-10903. [CrossRef]

11. Hundertmark, M.; Dimova, R.; Lengefeld, J.; Seckler, R.; Hincha, D.K. The intrinsically disordered late embryogenesis abundant protein LEA18 from Arabidopsis thaliana modulates membrane stability through binding and folding. Biochim. Biophys. Acta 2011, 1808, 446-453. [CrossRef] [PubMed]

12. Shih, M.D.; Hsieh, T.Y.; Lin, T.P.; Hsing, Y.I.; Hoekstra, F.A. Characterization of two soybean (Glycine max L.) LEA IV proteins by circular dichroism and Fourier transform infrared spectrometry. Plant Cell Physiol. 2010, 51, 395-407. [CrossRef] [PubMed]

13. Liu, G.; Xu, H.; Zhang, L.; Zheng, Y. Fe binding properties of two soybean (Glycine max L.) LEA4 proteins associated with antioxidant activity. Plant Cell Physiol. 2011, 52, 994-1002. [CrossRef] [PubMed]

14. Liu, G.; Liu, K.; Gao, Y.; Zheng, Y. Involvement of C-Terminal Histidines in Soybean PM1 Protein Oligomerization and Cu2+ Binding. Plant Cell Physiol. 2017, 58, 1018-1029. [CrossRef] [PubMed]

15. Eriksson, S.K.; Kutzer, M.; Procek, J.; Grobner, G.; Harryson, P. Tunable membrane binding of the intrinsically disordered dehydrin lti30, a cold-induced plant stress protein. Plant Cell 2011, 23, 2391-2404. [CrossRef]

16. Dang, N.X.; Popova, A.V.; Hundertmark, M.; Hincha, D.K. Functional characterization of selected LEA proteins from Arabidopsis thaliana in yeast and in vitro. Planta 2014, 240, 325-336. [CrossRef]

17. Oliver, A.E.; Hincha, D.K.; Crowe, J.H. Looking beyond sugars: The role of amphiphilic solutes in preventing adventitious reactions in anhydrobiotes at low water contents. Comp. Biochem. Physiol. A Mol. Integr. Physiol. 2002, 131, 515-525. [CrossRef]

18. Hincha, D.K.; Zuther, E.; Hellwege, E.M.; Heyer, A.G. Specific effects of fructo- and gluco-oligosaccharides in the preservation of liposomes during drying. Glycobiology 2002, 12, 103-110. [CrossRef]

19. Kovacs, D.; Kalmar, E.; Torok, Z.; Tompa, P. Chaperone activity of ERD10 and ERD14, two disordered stress-related plant proteins. Plant Physiol. 2008, 147, 381-390. [CrossRef]

20. Rantalainen, K.I.; Christensen, P.A.; Hafren, A.; Otzen, D.E.; Kalkkinen, N.; Makinen, K. Interaction of a potyviralVPg with anionic phospholipid vesicles. Virology 2009, 395, 114-120. [CrossRef]

21. Welker, S.; Rudolph, B.; Frenzel, E.; Hagn, F.; Liebisch, G.; Schmitz, G.; Scheuring, J.; Kerth, A.; Blume, A.; Weinkauf, S.; et al. Hsp12 is an intrinsically unstructured stress protein that folds upon membrane association and modulates membrane function. Mol. Cell 2010, 39, 507-520. [CrossRef] [PubMed]

22. Koag, M.C.; Fenton, R.D.; Wilkens, S.; Close, T.J. The binding of maize DHN1 to lipid vesicles. Gain of structure and lipid specificity. Plant Physiol. 2003, 131, 309-316. [CrossRef] [PubMed]

23. Koag, M.C.; Wilkens, S.; Fenton, R.D.; Resnik, J.; Vo, E.; Close, T.J. The K-segment of maize DHN1 mediates binding to anionic phospholipid vesicles and concomitant structural changes. Plant Physiol. 2009, 150, 1503-1514. [CrossRef] [PubMed]

24. Eriksson, S.; Eremina, N.; Barth, A.; Danielsson, J.; Harryson, P. Membrane-Induced Folding of the Plant Stress Dehydrin Lti30. Plant Physiol. 2016, 171, 932-943. [CrossRef]

25. Artus, N.N.; Uemura, M.; Steponkus, P.L.; Gilmour, S.J.; Lin, C.; Thomashow, M.F. Constitutive expression of the cold-regulated Arabidopsis thaliana COR15a gene affects both chloroplast and protoplast freezing tolerance. Proc. Natl. Acad. Sci. USA 1996, 93, 13404-13409. [CrossRef]

26. Thalhammer, A.; Bryant, G.; Sulpice, R.; Hincha, D.K. Disordered cold regulated15 proteins protect chloroplast membranes during freezing through binding and folding, but do not stabilize chloroplast enzymes in vivo. Plant Physiol. 2014, 166, 190-201. [CrossRef]

27. Hara, M.; Terashima, S.; Fukaya, T.; Kuboi, T. Enhancement of cold tolerance and inhibition of lipid peroxidation by citrus dehydrin in transgenic tobacco. Planta 2003, 217, 290-298. [CrossRef]

28. Tolleter, D.; Hincha, D.K.; Macherel, D. A mitochondrial late embryogenesis abundant protein stabilizes model membranes in the dry state. Biochim. Biophys. Acta 2010, 1798, 1926-1933. [CrossRef] 
29. Moore, D.S.; Hand, S.C. Cryopreservation of lipid bilayers by LEA proteins from Artemiafranciscana and trehalose. Cryobiology 2016, 73, 240-247. [CrossRef]

30. Wise, M.J.; Tunnacliffe, A. POPP the question: What do LEA proteins do? Trends Plant Sci. 2004, 9, $13-17$. [CrossRef]

31. Rahman, L.N.; Chen, L.; Nazim, S.; Bamm, V.V.; Yaish, M.W.; Moffatt, B.A.; Dutcher, J.R.; Harauz, G. Interactions of intrinsically disordered Thellungiellasalsugineadehydrins TsDHN-1 and TsDHN-2 with membranes-Synergistic effects of lipid composition and temperature on secondary structure. Biochem. Cell Biol. 2010, 88, 791-807. [CrossRef] [PubMed]

32. Hincha, D.K.; Oliver, A.E.; Crowe, J.H. Lipid composition determines the effects of arbutin on the stability of membranes. Biophys. J. 1999, 77, 2024-2034. [CrossRef]

33. Furuki, T.; Sakurai, M. Group 3 LEA protein model peptides protect liposomes during desiccation. Biochim. Biophys. Acta 2014, 1838, 2757-2766. [CrossRef] [PubMed]

34. Liu, Y.; Wu, J.; Sun, N.; Tu, C.; Shi, X.; Cheng, H.; Liu, S.; Li, S.; Wang, Y.; Zheng, Y.; et al. Intrinsically Disordered Proteins as Important Players during Desiccation Stress of Soybean Radicles. J. Proteome Res. 2017, 16, 2393-2409. [CrossRef] [PubMed]

(C) 2020 by the authors. Licensee MDPI, Basel, Switzerland. This article is an open access article distributed under the terms and conditions of the Creative Commons Attribution (CC BY) license (http://creativecommons.org/licenses/by/4.0/). 